\title{
Kolkata Flyover Collapse- April 2016
}

\author{
Nirmalendu Bandyopadhyay* \\ Independent Consulting Engineer, India
}

Submission: March 24, 2017; Published: April 24, 2017

*Corresponding author: Nirmalendu Bandyopadhyay, Independent Consulting Engineer, Kolkata, India, Email: nbanbdyopadhyay@hotmail.com

\section{Background}

Kolkata is the capital city of West Bengal state within the Indian Union. It covers an area of approximately 185sq. $\mathrm{km}$ and current population around 5 million. It is situated on the banks of the river Ganges (GANGA) and is one of the most densely populated cities in the country. To overcome the traffic congestion on the major roads in the business districts, the Govt has undertaken construction of several flyovers which has eased the traffic flow in certain localities. One of the recent ones is a $2.5 \mathrm{~km}$ stretch in Central Kolkata, having 2 serviceable roads with provision for expansion to 4 lanes in future as traffic flow grows. The location of the flyover is shown in the above map of the city.

Construction of the flyover started in 2007 and target completion was scheduled in 2009 to cater to the needs for uninterrupted construction. But due to various constraints specially in getting regulatory clearances as work site situation changed and also due to fund constraint, the contractor had financial difficulties in progressing as per schedule. There was change of govt in between so that the new target was set at 2014 . About $75 \%$ of the work was completed and it was expected that the facilities will be commissioned in 2016. Unfortunately, on March 26, 2016 part of the flyover structure collapsed causing loss of lives and damage to properties. The magnitude of the accident was so severe that Army had to be called in and it took over 6 days to clear the debris and rescue dead bodies trapped under the debris. It was a heart rendering scene. All photography and approach to the site was banned temporarily. Therefore, this write up is based on information, I could gather from various sources and there may be inadvertent omissions and mistakes (Figure 1-3).

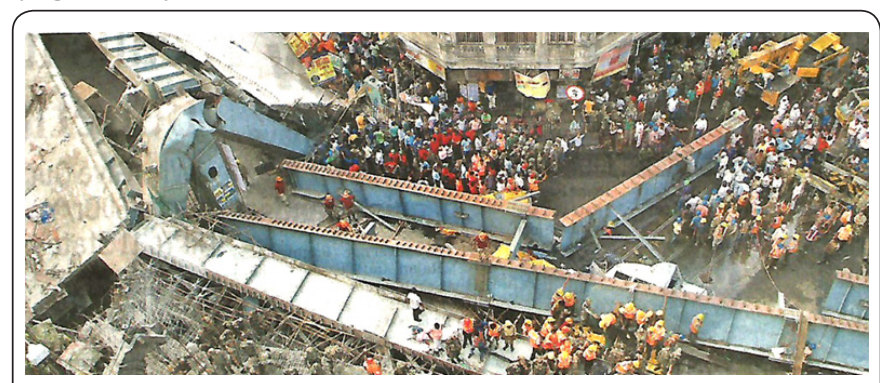

Figure 1 : Aerial View if the site after collapse
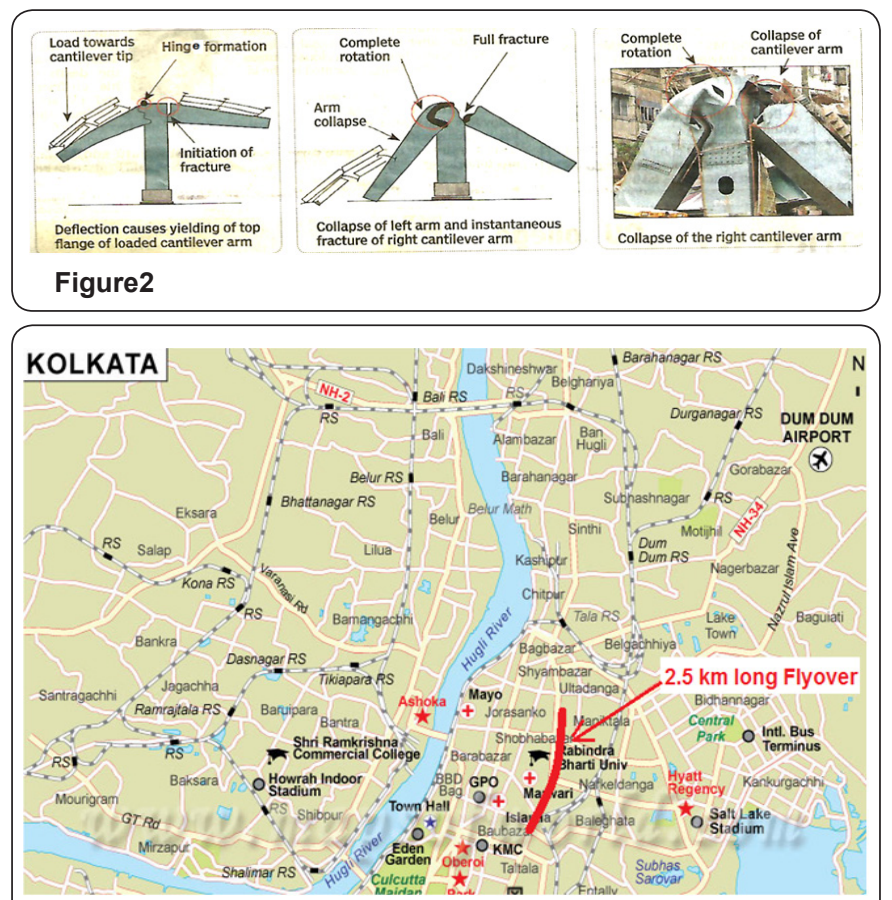

Figure 3

At the proposed workshop, I will try to analyze the factors that may have caused this mishap Few photographs and sketches are included in this analysis.

\section{Construction}

The flyover has to be constructed on a very busy stretch of the city road network. Therefore, the construction must not create hurdles to the traffic flow. Moreover, the area is highly congested so the project must be completed within very tight time schedule. Keeping all these factors in mind it was decided to adopt structural steel structures for the superstructure. Box girders were chosen for columns and beams forming rigid portal frames on RCC foundations supported on bored cast in pipes driven to $45 \mathrm{~m}$ below the $\mathrm{r}$ level. The soil is predominantly sandy clay with mix of gangetic alluvium having bearing capacity around $8 \mathrm{~T} / \mathrm{m}^{2}$. This required the piles to be on a bed of compact sand stone at average $45 \mathrm{~m}$ depth. Schematics of the construction shown below. 
To expedite the project completion and reduce site work, the super structure was designed using structural steel portal of box sections erected over RCC foundations supported on bored cast in situ piles driven $45 \mathrm{~m}$ under the GL where a layer of compact sandstone exists. On top of the steel super structure a cast in situ RCC slab $200 \mathrm{~mm}$ thick was designed topped by a $100 \mathrm{~mm} \mathrm{PC}$ wearing course and finally $50 \mathrm{~mm}$ thick mastic asphalt surfacing was laid. The live load was as per guideline of various codes and Ministry of Surface Transport, Govt of India. However, as the bridge was not commissioned at the time of accident, the live load was absent. Under this circumstance, the failure was due to other factors as analysed by Failure Mode Effect Analysis (FMEA) which has wide application in industrial plant projects from design stage. The same analogy can be applied in this case with slight difference as Failure Mode and Reason Analysis (FMRA). This is explained by the following diagram.

\section{Application of forensic engineering in root cause failure analysis (RCFA)}

In the absence of adequate design data, and restrictions on site visits, the analysis has to be based on scanty information available from various sources. Forensic engineering principles have been applied to ascertain the Root Cause Failure Analysis . It is to be noted that failure has occurred when the bridge was not subjected to any live load from moving vehicles. Thus, it can be inferred that there was some basic design deficiency. The longitudinal beams spanning between the portal hammer head frames had no bracings on the compression flanges to prevent lateral buckling. Such buckling imposed additional horizontal loads on the portal frame box girders. At the portal frame hammer heads the horizontal box girder beams should have extra depth at the knee joint to withstand additional moments resulting from moment redistribution according to stiffness of each member at the joint. The box girders should have internal ribs to withstand torsion forces resulting from torsion and buckling of the girders. The various stages for failure of the portal frame girders are shown below. Thus, it can be concluded that there were inherent design deficiencies from the beginning. The other contributory factors for failure can be attributed to inadequate QA/QC measures at shop and site during fabrication and site erection of the portal frames. Normal practice for acceptance of structural steel is to depend on mill test certificates. In such girders it is advisable to carry out USG tests and Pulse echo testing of steel plates to ascertain that they are free from internal defects. From the failure pattern of the top flange plates of the portal frame box girders, it is clear that there were internal defects inside the plates causing rupture and eventual failure of the top flange. Also the thick plates should have undergone preheating and imposition of inter pass temperature guidelines during welding. It is doubtful how much these were done during fabrication and assembly of the box girders. In the absence of such practice, there is bound to be inbuilt residual stresses inside the plates which lower the yield stress level and are apt to fail when loads come on them (Figure 4-6).
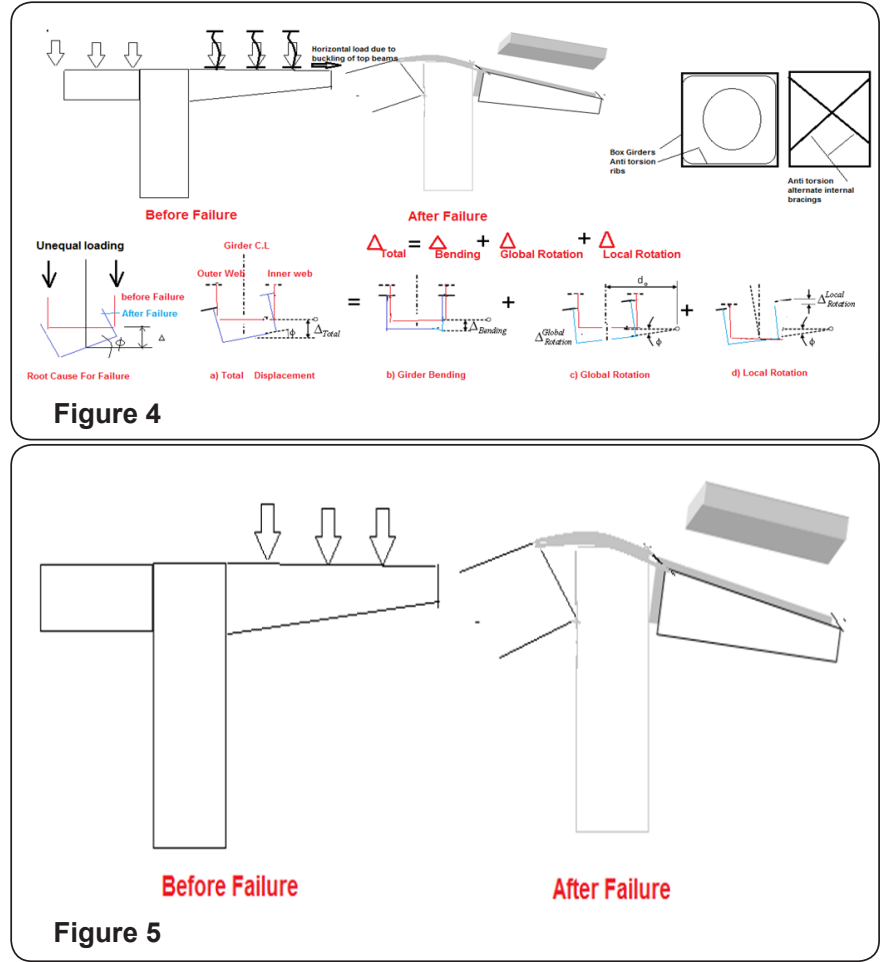

\begin{tabular}{|c|c|c|}
\hline \multirow[b]{2}{*}{ Collapse } & \multicolumn{2}{|l|}{ Failure Mode } \\
\hline & Deformation & Unserviceable \\
\hline $\begin{array}{l}\text { Flexure } \\
\text { Shear } \\
\text { Twisting }\end{array}$ & $\begin{array}{l}\text { Bending } \\
\text { Deflection } \\
\text { Torsion }\end{array}$ & $\begin{array}{l}\text { excessive deformation } \\
\text { damage to road } \\
\text { impediment to traffic }\end{array}$ \\
\hline
\end{tabular}

Figure 6 : By analyzing the photographs, it is clear that the collapse has occurred due to the combination of all the reasons outlined above.

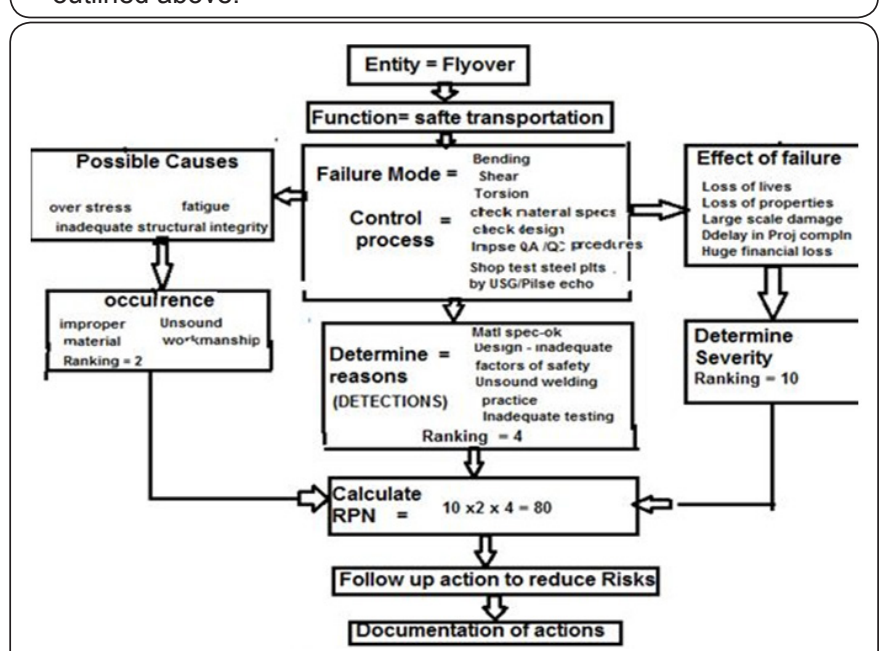

Figure 7 : This is explained briefly through the Fault Tree Analysis (FTA).

At the workshop all these will be analyzed in details and sample design calculations due to non availability of specific design data, the principle of Reverse Engineering Technology will be demonstrated (Figure 7 \& 8). 


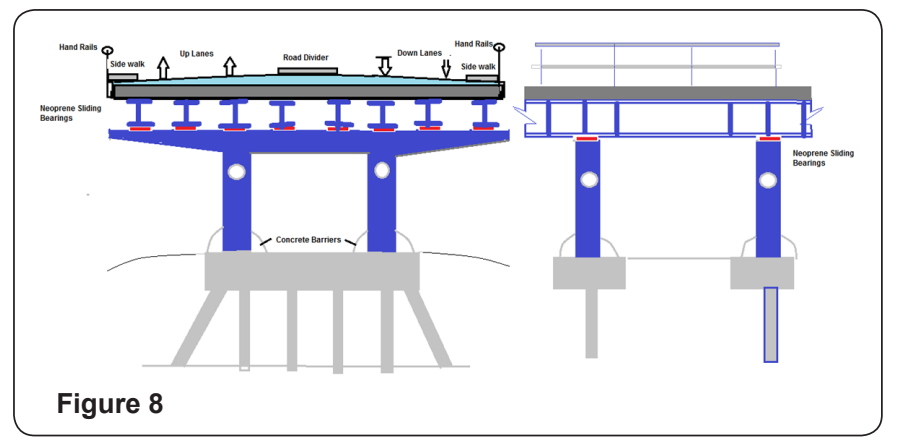

Risk priority number (RPN): Risk priority number methodology is a technique for analysing the risk associated with potential failures during a FMEA analyses. To calculate risk priority number, severity, occurrence, and detection are the three factors need to determine.

$\mathrm{RPN}=$ Severity $\times$ Occurrence $\times$ Detection (reasons) $=10 \times 2 \times$ $4=80$

In this case since Severity is the main contributor to the RPN Value, therefore, failure can be categorised as highly hazardous

Occurrence (0): Occurrence ratings for FMEA are based upon the likelihood that a cause may occur based upon past failures and performance of similar system in similar activity. Occurrence values should have data to provide justification. An example rating for occurrence is given in the (Table 1).

Table 1: Example of table detection.

\begin{tabular}{|c|c|c|}
\hline \multicolumn{3}{|c|}{ Example of Table detection } \\
\hline Rating & Detection & Detection by design control \\
\hline 10 & $\begin{array}{l}\text { Absolute un } \\
\text { certainty }\end{array}$ & Design control cannot detect failure mode \\
\hline 9 & Very remote & $\begin{array}{l}\text { Very remote chance the design control } \\
\text { detect failure mode }\end{array}$ \\
\hline 8 & Remote & $\begin{array}{l}\text { Remote chance the design control detect } \\
\text { failure mode }\end{array}$ \\
\hline 7 & Very low & $\begin{array}{c}\text { Very low chance the design control detect } \\
\text { the failure mode }\end{array}$ \\
\hline 6 & low & $\begin{array}{l}\text { Low chance the design control detect the } \\
\text { failure mode }\end{array}$ \\
\hline 5 & Moderate & $\begin{array}{l}\text { Moderate chance the design control } \\
\text { detect failure mode }\end{array}$ \\
\hline 4 & Moderately high & $\begin{array}{l}\text { Moderately high chance the design } \\
\text { control detect failure mode }\end{array}$ \\
\hline 3 & High & $\begin{array}{l}\text { High chance the design control detect } \\
\text { failure mode }\end{array}$ \\
\hline 2 & Very high & $\begin{array}{l}\text { Very high chance the design control } \\
\text { detect failure mode }\end{array}$ \\
\hline 1 & Almost certain & Design will control detect failure mode \\
\hline
\end{tabular}

Detection (D) (Reasons): Detection is an assessment of the likelihood that the current controls will detect the cause of failure mode. An example for detection is as shown in (Table 2 \& 3).

Table 2: Example table of severity.

\begin{tabular}{|c|c|c|}
\hline \multicolumn{3}{|c|}{ Example Table of Severity } \\
\hline Ranking & Effect & Severity effect \\
\hline 10 & $\begin{array}{l}\text { Hazardous without } \\
\text { warning }\end{array}$ & Very high severity without warning \\
\hline 9 & $\begin{array}{l}\text { Hazardous without } \\
\text { warning }\end{array}$ & Very high severity with warning \\
\hline 8 & Very high & Destructive failure without safety \\
\hline 7 & High & $\begin{array}{l}\text { System inoperable Equipment } \\
\text { damage }\end{array}$ \\
\hline 6 & Moderate & $\begin{array}{l}\text { System inoperable with minor } \\
\text { damage }\end{array}$ \\
\hline 5 & low & System inoperable without damage \\
\hline 4 & Very low & Degradation of performance \\
\hline 3 & Minor & $\begin{array}{l}\text { System operable with some } \\
\text { degradation in performance }\end{array}$ \\
\hline 2 & Very minor & $\begin{array}{l}\text { System operable with minor minimal } \\
\text { interference }\end{array}$ \\
\hline 1 & None & No effect \\
\hline
\end{tabular}

Table 3: Example table occurrence.

\begin{tabular}{|c|c|c|}
\hline \multicolumn{3}{|c|}{ Example Table of Occurrence } \\
\hline Rating & Classification & Example \\
\hline 10 & Very high & Inevitable failures \\
\hline 9 & Very high & Inevitable failures \\
\hline 8 & High & Repeated failures \\
\hline 7 & High & Repeated failures \\
\hline 6 & Moderate & Occasional failures \\
\hline 5 & Moderate & Occasional failures \\
\hline 4 & Low remote & Few failures \\
\hline 3 & Low remote & Few failures \\
\hline 2 & Remote & Failures unlikely \\
\hline 1 & Remote & Failures unlikely \\
\hline
\end{tabular}

